\title{
Designing A World-Class Health Care System
}

\author{
Howard J. Bolnick*
}

\begin{abstract}
Public health systems are finding it increasingly difficult to fund all the health care that their citizens want and need. Fiscal constraint is causing many nations to reconsider the respective roles of their public programs and private health insurance. The author examines the potential for and performance of health systems around the world and the advantages and disadvantages of public and private health financing. This analysis leads to the development of a framework for improvements in today's mix of health care financing and to high-level principles for a better-coordinated relationship between public and private programs. The role of health actuaries in moving toward more effective health systems is then explored.
\end{abstract}

\section{INTRODUCTION}

Since the dawn of civilization health care has been a focus of public and government interest. As early as 1700 B.C.E., Hammurabi, ruler of Babylon, developed laws on health care matters that included access to services, payment for care, and quality control. Hammurabi's Code of Law (King 1910) declares:

- Cost: "If a physician make a large incision with an operating knife and cure it, or if he open a tumor (over the eye) with an operating knife, and saves the eye, he shall receive ten shekels in money" (law 215).

- Access: "If the patient be a freed man, he (the surgeon) receives five shekels. If he be the slave of some other, his owner shall give the physician two shekels" (laws 217-218).

- Quality: "If a physician make a large incision with the operating knife, and kill him, or open a tumor with the operating knife, and cut out the eye, his hands shall be cut off" (law 218).

While our sensibilities about acceptable approaches to stewardship of our systems certainly differ from Hammurabi's, these same three issues of cost, quality, and access continue to shape ongoing debates over health care systems around the world.

\footnotetext{
* Howard J. Bolnick, F.S.A., Hon.F.I.A., M.A.A.A., is Chairman and CEO of InFocus Financial Group Inc., 30 N. LaSalle St., Suite 3440, Chicago, IL 60602, e-mail: hbolnick@kellogg.northwestern.edu.
}

Nations throughout the world are faced with growing demands on their health care systems, often accompanied by diminishing abilities to satisfy and pay for all the health care needs and wants of their citizens. The purpose of this paper is to develop an international perspective on health care systems and a preferred general direction of change that allows policymakers (including actuaries) and politicians to adapt to universal supply and demand pressures.

The health care sector of the global economy is huge: Its issues are many and they are exceedingly complex. Arguments over trade-offs between social solidarity versus personal autonomy, public versus private health care financing, public versus private provision of health care services, and the need for high-quality medical care versus more basic levels characterize health care debates in virtually every nation. Yet, to move forward, we must understand these enormously complicated problems and find a path that moves us toward executable health care policies.

To help in this quest, this paper explores recent evolution in international thinking about what might constitute an "ideal" world-class health care system-a public system offering basic health care to all citizens, complemented by a private system providing for the nonessential health services that many citizens want, but do not need, to attain world-class health outcomes. The path to understanding what constitutes an "ideal" system covers a wide range of consider- 
ations. A brief overview of this paper's structure follows.

- The paper begins by describing important personal, social, economic, and political drivers of health care and health care systems. These nonmedical factors greatly affect the shape of nations' health care systems and account for the wide diversity in how they are organized.

- It then discusses health care systems' goals and presents a generalized structure for how systems are organized to fulfill their societies' goals.

- Next, I use comparative data from the World Health Organization's (WHO 2000) World Health Report 2000 to look at the world's 191 health care systems. This analysis leads to identifying 24 "world-class" health care systems and key characteristics that separate these systems from others.

- The worldwide comparison then is extended to a more thorough analysis of the U.S. and U.K. health care systems. Based on differing nonmedical drivers, these two "world-class" systems adopted very different structures to satisfy their citizens' health care goals.

- Next, I explore the economic characteristics of private and public insurance markets: How choice of market structure affects health care systems' performances and the ability of systems to fulfill societies' goals.

- Lessons learned from the analysis are then used to describe an ideal health care system, with "ideal" being a very general statement of preferred design principles. These principles leave room for differences among health care systems. This is necessary, since each nation's personal and social sensitivities, its economic system, and its politics are all hugely important in shaping the particular structure of its health care system. There is no one-size-fits-all health care system. Thus, the "ideal" system presented is not a specific design; nor does it provide a uniform prescription for change or endorse any particular political health care reform proposal in the United States or other countries.

- Lastly, I discuss how actuaries can play important roles as national health care systems continue to evolve.

The World Health Report 2000 (WHO 2000) is a major source of conceptual information and most of the data used in this paper. This report presents a structure and data to measure and compare the worlds' 191 health care systems. This was an enormous undertaking by WHO researchers, and not one without controversy. Interested readers will want to refer the report itself for a detailed description of the data, data collection methods, and limitations on it's reliability and use. References are also provided in Section 6 to sources critical of the validity of these data.

\section{Health Care Systems Potentials}

\subsection{Health Ideals}

All modern, well-developed health care systems share a common goal for those who depend on their services: hope for full and healthy lives. The personal importance of this goal inevitably means that health care is much more than an ordinary economic good or service. Good health is a state of being that is necessary for each of us to have the opportunity to fully express our human selves and to be able to reach our human potential. Our national health care system, whether public or private or mixed, is the social and economic expression of support for our individual good health.

The personal importance of good health and health care systems is well expressed by health ethicists Roberto Mordacci and Richard Sobel (1998).

"Health can be seen as a means, a foundation for achievement, as a first achievement itself, and a necessary premise for further achievement .... The sick individual suffers isolation, loss of freedom to act, loss of the familiar world; the future is in doubt and all attention is concentrated on the present . . . . When ill, we no longer trust our bodies and... we no longer trust life" (p. 34).

No wonder health care financing and provision for health care services are such sensitive public issues.

Personal importance of health drives societal expectations for health care systems. The sensitive nature of health and health care led WHO to adopt an expansive and controversial definition of health in the preamble to its 1946 constitution. This "ideal" definition of "health" as a goal for WHO and its member nations' health care systems is: "a state of complete physical, mental and social well-being and not merely the absence of 
disease or infirmity" (WHO 2000). This definition clearly moves beyond medical care and can easily be read to include a wide range of nonmedical care outcomes (e.g., housing, nutrition, education, adequate income).

As an "ideal," this definition of health is hard to fault. However, as a practical definition driving goals and objectives for the world community's health care systems, it is far too expansive and, therefore, wildly unrealistic as a guide to policy. As unrealistic as it is as a goal for national health systems, a state of complete well-being does seem to drive personal expectations for health, particularly in higher-income nations with well-developed health care systems. Ethicist Daniel Callahan (Callahan 1998) of the Hastings Center has criticized the U.S. health care system as actually reaching for an implicit goal of providing "all the care we 'want' and 'need,' when we want it!" He argues that fulfilling this expansive expectation is impossibly expensive and that this is a major reason that the U.S. health care system is so much more expensive than those of other nations. A key aspect of Callahan's criticism to note is his distinction between care citizens "need" that is less than the care and amenities they "want." Separating "wants" from "needs" is an important part of this analysis.

\subsection{Ethics/Ethos and Politics Shape a System's Potential}

How these medical care "wants," "needs," and personal expectations are fulfilled in a nation's health care system is driven by a number of nonmedical considerations. Ethics and politics are two considerations that have profound affects on how a nation organizes the financing and provision of medical care for its citizens.

The body politic of nations differ in their societal ethic. The distinction between social solidarity and personal autonomy is an important driver underlying a nation's choice between public and private health care systems. At the extremes of this dimension are the U.K. health care system and the U.S. system.

The United Kingdom adopted its public health care financing and delivery system as a "reward" to itself following the turmoil and pain of World War II. Social Insurance and Allied Services (Beveridge 1942), also known as the "Beveridge
Report," laid the foundation for creation in the United Kingdom of a National Health Insurance (NHI) program. Reading the "Beveridge Report," I was struck by the almost total absence of argument for a scheme based on social solidarity rather than personal autonomy. The report implicitly assumes that the British body politic social ethic accepts a strong sense of equality and pursuit of common well-being among U.K. citizens as an essential ethic that should underlie their health insurance scheme.

At the other extreme, periodic health care reform debates in the United States show strong bias on the part of the American body politic for personal autonomy over social solidarity.

Medical decision-making ethics also strongly affect the choice between public and private provision of health care services. Whether an ethic prevails that favors state paternalism, patient autonomy, or professional paternalism makes a strong difference. Using as our extremes the U.S. and U.K. health systems, we can better understand this ethics-driven choice.

Since early in the development of modern medicine, physicians in the United States have created and strongly defended a private health care delivery system that gives them a great deal of autonomy and professional paternalism (Starr 1982). In contrast, in the United Kingdom, federal government tightly controls NHI. State paternalism reins in the U.K. health care system, in large part because it is ethically acceptable to U.K. physicians. It should be noted that, as citizens become more educated on health and health care matters, both of these systems are adopting more of a patient autonomy ethic.

Family ethic also drives the shape of a nation's health care system. For example, in nations with strong intergenerational family bonds, much of the care support for patients, particularly those with long-term chronic conditions and infirmaries of aging, are taken care of by families. In nations with looser intergenerational family bonds, patients often demand nonmedical care support from the medical care system. A loosening of family ties is characteristic of most developed nations, including the United States and the United Kingdom.

Political-economic ideology, political power centers, and the political decision-making process all also have strong affect on a nation's health 
care system. It does not take strong argument to see that a collective-socialist society will favor public health care programs and that private programs will more likely find favor in free-market economies. Political decisions will also be influenced by the relative political power and ideology of health care providers, consumers, and bureaucrats. The United States has a deserved reputation for favoring free-market economics, whereas the U.K. system has a more socialist character to its free-market economic system.

Lastly, the decision-making process itself will affect the potential for change. The U.S. tripartite power sharing among the President, Congress, and the courts makes change more difficult than in a parliamentary government (e.g., as practiced in the United Kingdom), or, even more clearly, than in an authoritarian government.

As I argue here, health care systems are shaped by important external nonmedical factors. Health is fundamentally important to human existence. Designers of health systems can expect almost constant public pressure to "do more." What can be done, and what needs to be done, then, is shaped by the social ethics, economics, and politics of each nation. These differences among nations make it certain that no "one-size-fits-all" health care system solution exists. External factors are too important and differ too much among nations for a detailed ideal health care template to exist.

\section{Goals for Health Care Systems}

As means to an end of good health, those responsible for stewardship of health care systems adopt goals for their work. These goals almost invariably contain elements related to the same three criteria promulgated on by Hammurabi: cost, quality, and access. These three goals are "ideals" that citizens and those who steward health care systems debate and strive to reach. Actual health care system performance quite often falls short of fulfilling these goals. ${ }^{1}$ One major reason for a performance gap is that assessing and measuring

\footnotetext{
${ }^{1}$ There is a particularly large gap in the United States between goals and performance. This gap reflects a particular social, economic, and political environment. See (Bolnick 1995) for a discussion of the differences between U.S. goals and performance and reasons for the gap.
}

cost, quality, and access as well as their interrelationships and trade-offs are quite difficult.

In 1978, in its "Declaration of Alma-Ata," WHO developed a goal of "Health for All" by the year 2000: "delivery to all of high-quality essential care, defined by criteria of: effectiveness, cost, and social acceptability." While this goal has not yet been reached, it has been integrated into WHO's work in developing nations and continues to serve as its vision. And, very important to our purposes, this goal serves as the basis for WHO's research into better understanding and measuring the performance of health care systems around the world.

Two other examples drawn from developed nations with very different health care systems are helpful to this exploration. The two nations are the United States, which is characterized by its large private health care sector, and the United Kingdom, with its almost exclusive public health care sector.

There is no "official" U.S. goal. However, a reading of various government and private reports from all parts of the political spectrum reveals a generally shared goal for "universal aceess to high-quality, comprehensive, cost-effective health care" (Bolnick 1995). The U.K. NHI does have a stated goal. It is to provide "comprehensive, high-quality medical care to all citizens on a basis of meeting professionally judged medical needs and without financial barriers to access" (Institute of Directors 2000). These are two vastly different systems in terms of structure and performance and, yet, their goals consist of quite similar criteria for cost, quality, and access.

Our discussion to this point has uncovered a number of important facts.

- Health is of vital importance to each of us; therefore, health care is important to the "body politic" and national government.

- Stewardship of the health care system is a vital government function.

- All health care systems have cost, quality, and access goals.

- Specific characteristics of each national health

\footnotetext{
${ }^{2}$ The Declaration of Alma-Ata was adopted at the Joint WHO/UNICEF International Conference on Primary Health Care held in Alma-Ata, U.S.S.R. (now Almaty, Kazakhstan) in 1978.
} 
care system are shaped by its personal and social ethics, economics, and political drivers.

\section{A Changing Mix of Public-Private FinANCING}

In the 1990s, and most notably under the leadership of Director-General Gro Harlem Brundtland, M.D. (1998-present), WHO has shifted its objectives for realizing the ambitious Declaration of Alma-Ata toward a "new universalism." Figure 1 is an overview of how goals for health care systems have evolved from expansive "classical universalism" of the Declaration of Alma-Alta into the new universalism.

New universalism adopts two important themes for national health care systems. First, it recognizes that it is not possible or realistic to have as a goal provision of all possible health care for everyone. As the potential array of health care services grows, and the cost of providing these services to everyone increases faster than economic growth, governments increasingly reach fiscal limits on services they can afford to deliver.

Second, WHO recognizes that, as government funded health care systems are forced to contract relative to a goal of providing all services for everyone, the private sector increasingly plays an important role in providing for citizens' health care demands. If the first priority is to provide services to all, then not all health care services can be provided. An acceptable, less comprehensive standard must be found.

WHO is not alone in incorporating a solid dose of health care realism into its goals and objectives. For example, European Union (EU) member nations have historically depended on public health care systems funded by the state (taxes) or social insurance premiums and made available to

\section{Figure 1}

\section{WHO's Changing Notions of Coverage and Scope of a Health Care System}

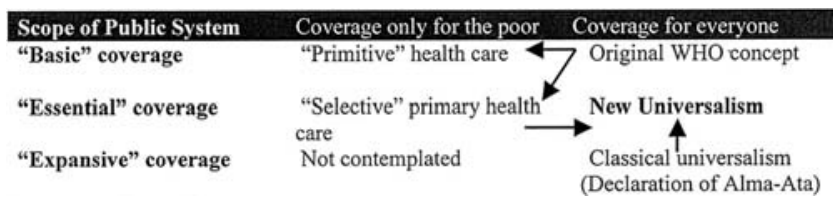

Source: WHO (2000), p. 15. all citizens regardless of their ability to pay (classical universalism). Fiscal constraint is making it more difficult to continue this policy. While voluntary (private) health insurance (VHI) has not played a big role in most EU nations, policymakers are increasingly looking at VHI as a possible means to take pressure off public programs (Mossialos and Thomson $2001^{3}$ ).

The EU's slow move towards health systems with more private financing (and often private provision of health services) is aided by the 1994 third nonlife directive from the EU Commission. This directive establishes a single market for VHI in the EU and abolishes national controls on premiums and policy conditions in order to increase competition and consumer acceptance. More recently, the EU Commission is moving toward a notion that the EU is a single health care market with need for freedom of movement across borders and, therefore, ultimately a single health care system encompassing the entire community.

\section{Health Systems Structure and Measurable Objectives}

All health care systems must perform an array of functions designed to measure objectives, the ultimate objective of a health care system being health itself. This section describes a framework and measurable objectives developed by WHO and presented in its report (WHO 2000). Figure 2 summarizes these functions and objectives and the interactions among them.

To work effectively, a health care system must perform four high level functions. Delivering services is the most visible of these functions. However, in order to deliver services, a health system must first be effective at creating resources through investment and training. Funds for resource creation and service delivery are an essential lubricant; therefore, health systems must also arrange financing. Funds must be collected, pooled, and ultimately used to purchase needed goods and services.

The concept of stewardship occupies a distinctive place in this functional overview. Stewardship is defined by WHO (2000) as a "function of

\footnotetext{
${ }^{3}$ This paper provides a valuable comprehensive study of $\mathrm{VHI}$ in the European Union.
} 
Figure 2

\section{Health Care Systems Overview}

Functions the system performs Objectives of the system

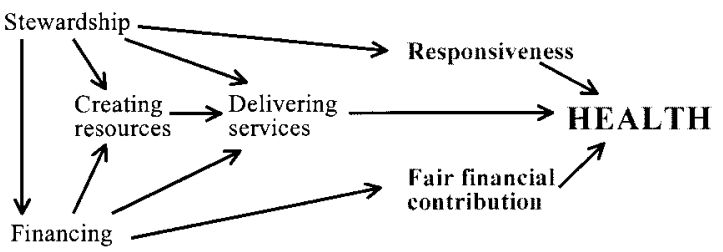

Source: WHO (2000).

government responsible for the welfare of the population, and concerned about the trust and legitimacy with which its activities are viewed by the citizenry" (p. 119). Economic activities of financing, creating resources and delivering services each might take place in either the public or private sectors.

Stewardship is best understood as a broad concept. A national health care system might choose to centralize stewardship in a single government agency, such as its health ministry. Alternatively, stewardship might be shared among various branches or levels of government. Government also might delegate some stewardship functions to the private sector. At an extreme, a government decision to leave health care solely to the private sector, with no government involvement or oversight, can be understood as "stewardship" based on faith in private-market solutions to social issues. Even in this extreme case, government is ultimately responsible to its citizenry for the performance of its health care system through the nation's political system.

Health care systems function to provide for population health needs. Fulfilling these needs is the system's objective. Health is clearly the most basic objective. WHO (2000) notes:

“... while improving health is clearly the main objective of a health system, it is not the only one. The objective of good health itself is really twofold: the best attainable average level-goodness — and the smallest feasible differences among individuals and groups-fairness. Goodness means a health system responding to what people expect of it; fairness means it responds equally well to everyone, without discrimination" (p. xi).
Based on this notion of how health eare systems perform, WHO adopts three fundamental objectives. These are:

- Improvement of the health of the population served.

- Responsiveness to citizen's expectations of their "needs" and "wants."

- Financial fairness in providing protection against the costs of poor health.

WHO researchers then developed measures of goodness (level) and fairness (variability) for each of these three objectives and gathered data to create a ranking for each of its 191 member nations. Levels attained on these measures and national rankings are reported in the Statistical Annex to the report (WHO 2000, Tables 1, 5, 6, and 7$)$.

WHO ranks nations on two overall measures and an alternative measure of health level:

- Overall Attainment of Objectives is a weighted average measure of attainment of goodness and fairness objectives for each nation.

- Overall Health System Performance is a weighted average measure of attainment versus what each system should be able to accomplish given their health resources.

- Health Performance is a measure of health attainment-disability adjusted life expectancy (DALE) - versus what each system should be able to accomplish given its health resources.

Detailed information about these measures can be found in the report, which is available for download on the WHO Web site at http://www. who.org.

The following analysis uses WHO's objective measures and rankings to analyze existing health care systems and help us to develop a framework for an ideal health care system. Given the importance of these data to our exploration, we must recognize that $\mathrm{WHO}$ has been both praised and criticized for its work. Some of its measures are well developed and well known to health policy analysts, DALE being the most important among them (Murray and Lopez 1996). Others, particularly measures of responsiveness and financial fairness, are new, and data underlying specific measures are sometimes scarce or virtually nonexistent.

WHO has made a commitment to continual 
improvements in its measurements and data gathering techniques. This commitment is being widely praised. However, WHO has also been criticized for the lack of scientific, totally objective data for some of its new measures, and the value of its various national rankings have been questioned (Williams 2001 and Almeida et al. 2001). ${ }^{4}$

\section{World Health Care Systems Performance}

WHO data can be used to demonstrate useful lessons about spending and performance of worldwide health care systems. It should come as no surprise that health spending varies enormously across the world. Using as our measure health spending as a percentage of gross domestic product (GDP), Figure 3 demonstrates this point.

The United States is the world champion health care spender, devoting $13.7 \%$ of its GDP. This is fully $3.2 \%$ of GDP higher than the second-place spending habits of Germany (10.5\% of GDP) and 5.5\% of GDP higher than the $8.2 \%$ average of all 15 EU member nations. For comparison purposes, U.K. health care spending is near the bottom of EU nations at $6.8 \%$ of GDP. Spending by the 29 Organization for Economic Cooperation and Development (OECD) member nations, which ranges from 6\% to $10 \%$ of GDP, is an even broader indicator of developed nations' financial commitment to health care.

At the other extreme of health care spending are poor nations, particularly those in Sub-Sahara Africa where tropical diseases ravage the population. The two nations that spend the least as a percentage of their GDP towards health care are Nigeria (3.1\% of GDP) and Niger (3.5\% of GDP). Their spending deficiency is even more obvious when translated into U.S. Dollars at the official exchange rate. Using this measure, Nigeria spends $\$ 30$ U.S. per person per year and Niger, only $\$ 5$ U.S. while the United States spends $\$ 4,187$ U.S., U.K. spends $\$ 1,303$ U.S., and the E.U. averages $\$ 1,868$ U.S.

WHO researchers use DALE as their most basic measure of health. DALE is a variation on the more familiar measure of overall population life

\footnotetext{
${ }^{4}$ Based on a review the WHO data and discussions of their accuracy and usefulness, I am comfortable that any problems do not materially affect the conclusions drawn by their use in this paper. However, careful readers will want to draw their own conclusions based on their own study of the WHO report and published criticism and commentary.
}

expectancy (Murray and Lopez 1996). Rather than simply measuring survival from birth to death, DALE reduces life expectancy by a measure of years lost to disability and infirmary. This gives an overall population measure of average years of disability-free life from birth.

DALE is a useful and valid means of measuring both the absolute and relative health of national populations. As a measure of population health, DALE captures the effectiveness of a nation's health care system as well as its public health programs, social and economic policies, and population's personal health habits. Figure 4 presents DALEs for nations with a DALE of 70.0 years or more and the three EU member nations that fall just short of this level of health.

The world's healthiest overall population is Japan's, with 74.5 years DALE. Twenty-four nations have a DALE of 70.0 years, ${ }^{5}$ which can be considered as a "world-class" health outcome. The United States ranks No. 24 at 70.0 years, the United Kingdom ranks No. 14 at 71.7 years, and the $15 \mathrm{EU}$ member nations average 71.4 years DALE. At the other extreme, the world's least healthy populations are found in Sub-Sahara Africa: Sierra Leone ranks No. 191 at 25.9 years and Niger ranks No. 190 at 29.1 years DALE.

There are vast differences in DALE between the healthiest and least healthy nations of the world community. Most of the difference is explained by survival rates and not by years alive with disability. In the healthiest nations, disability-adjustments reduce life expectancy by about $10 \%$. For example, life expectancy at birth in Japan is 80.0 years, compared to 74.5 years of DALE. In the least healthy nations, this adjustment amounts to $20 \%$ of life expectancy. Sierra Leone has 34.3 years life expectancy versus 25.9 DALE.

The health profiles of populations in the healthiest nations also are very different from those of the least healthy nations. WHO measures this burden of disease using the number of disability-adjusted life years (DALYs) lost to various diseases (Murray and Lopez 1996). Figure 5 compares DALYs by category for high-income versus low- and middle-income nations. Developed nation's burden of disease is

\footnotetext{
${ }^{5}$ The choice of 70.0 years DALE as "world-class" is an arbitrary cutoff used for this paper. The U.S. rank as No. 24 at exactly 70.0 years DALE is a fortuitous consequence of this cutoff.
} 
Figure 3

World-Class Health Care Systems' Costs

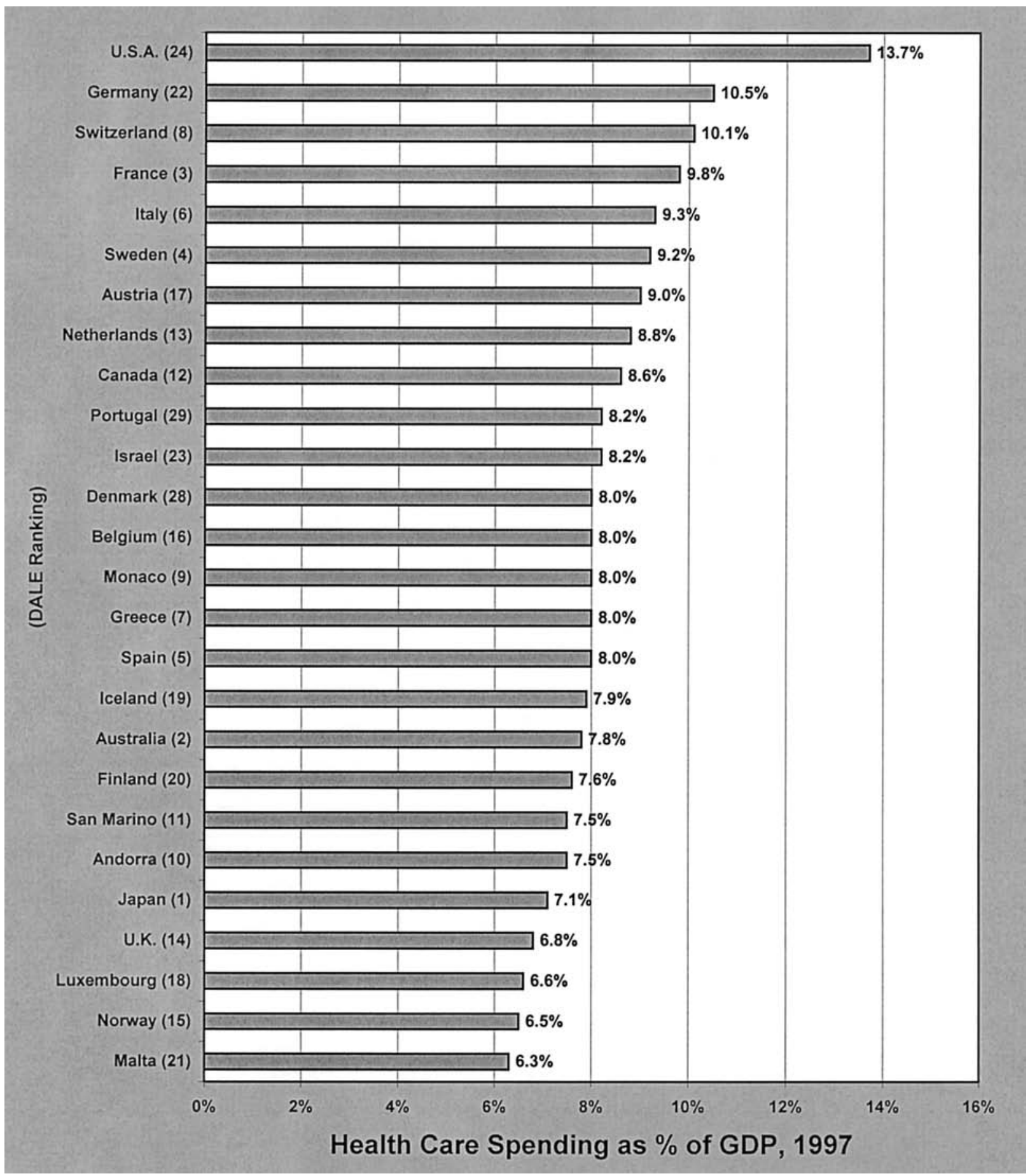

Source: WHO (2000).

Note: National rankings (in parentheses) are by health attainment, which WHO researchers measure by disability adjusted life expectancy (DALE).

heavily caused by chronic diseases. Low- and middle-income nations bear a severe burden of infectious disease and diseases of childbirth. Most of these infectious diseases are endemic solely in tropical areas, or they are public health problems that either do not exist or have been well managed in 
Figure 4

\section{World-Class Health Attainment}

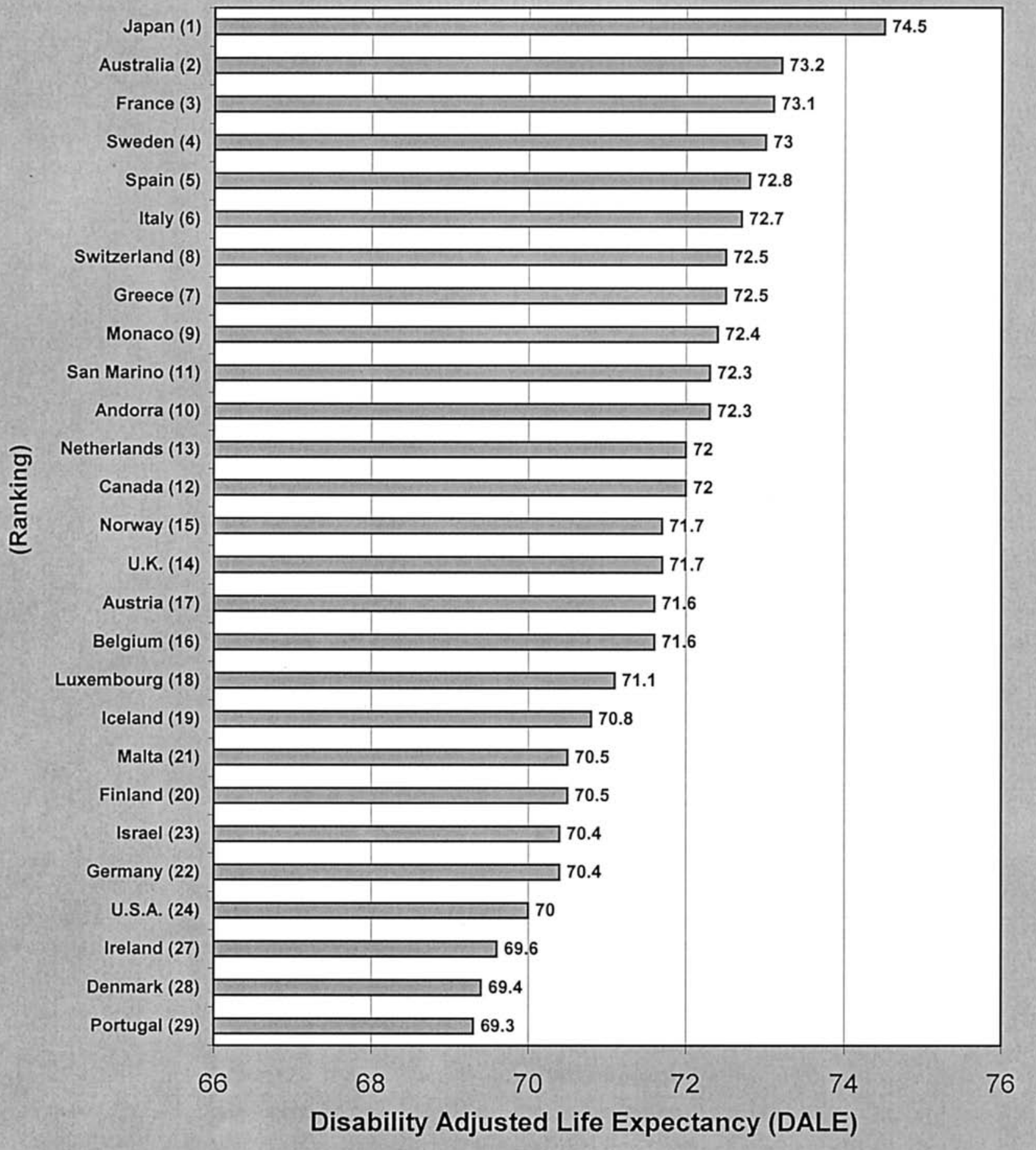


Figure 5

\section{Disease Burden}

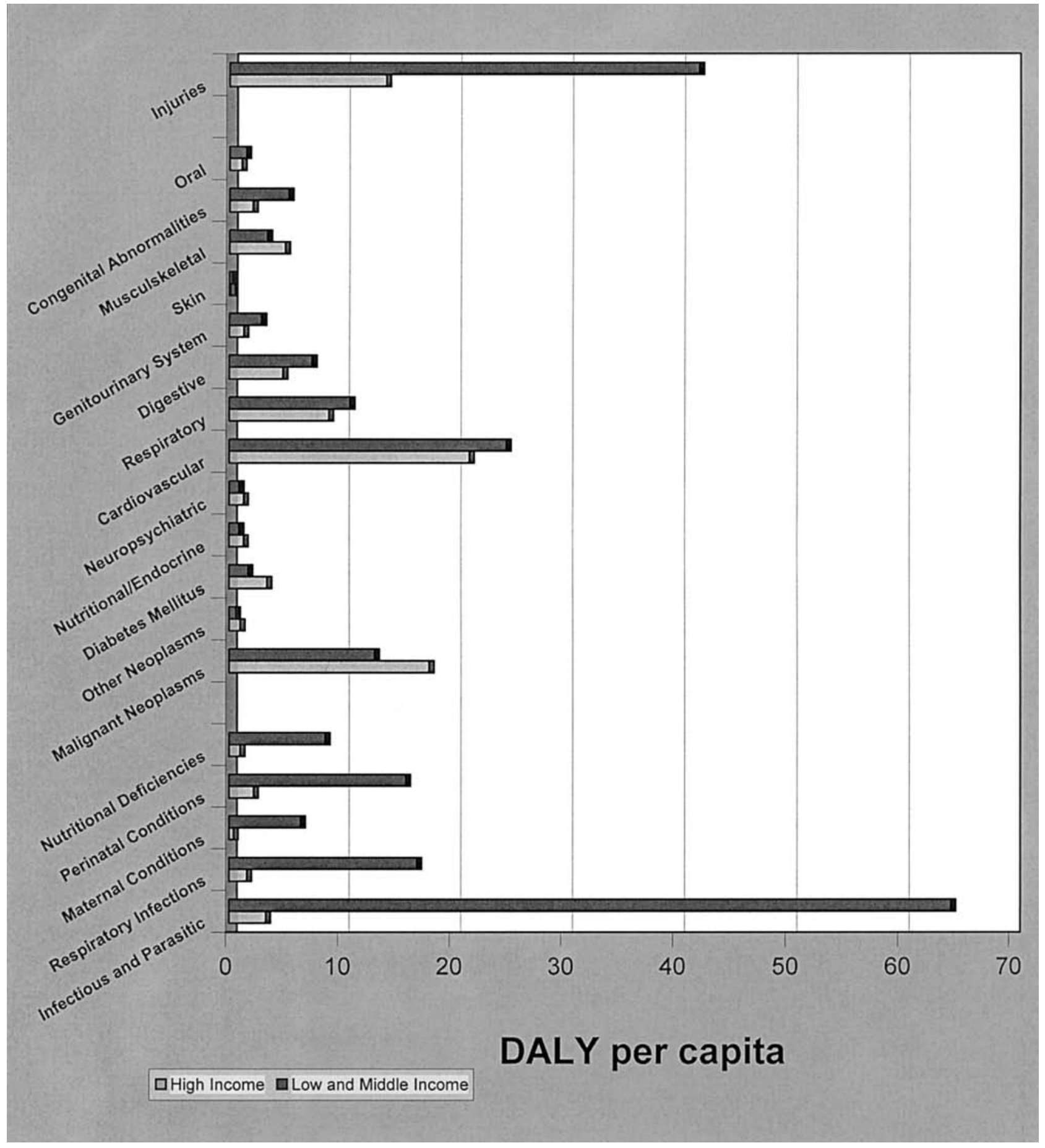

high-income nations. In addition, low-income nations suffer from a very high burden due to injuries relative to the burden in middle- and high-income nations. Developing nations' burden of disease is heavily weighted toward infectious disease, diseases of childbirth, and accidents. There has been a great deal of thinking done about how to address this morbidity profile (Sachs 2001). Researchers 
note that much of this disease burden is amenable to basic public health intervention. Clean water, sewage treatment, basic prenatal and postnatal care, accident prevention, and other simple interventions that we in developed nations take for granted can greatly reduce these health problems.

Almost all developed nations have built their health care systems on heavily public-funded models. The major exceptions to this are the United States and South Africa. Figure 6 displays data on the size of public health care expenditures (as a percentage of total health care costs) compared to health outcomes (measured by DALE). If there were inherent advantages to public versus private health care systems, the data should reveal a clear correlation between DALE and size of nations' public sectors. A glance at the figure, though, shows no such correlation.

While the mean for public health care spending is greater than $50 \%$ of total spending, higher public percentages do not result in greater numbers of years spent free from illness. This is an important observation, since the serious political and policy question of public versus private health care systems cannot be answered solely by a positive correlation with health outcomes.

The segment of data from the 24 "world-class" national health care systems, those with 70.0 or more years of DALE, demonstrates this point. At the extremes are the United States, with 70.0 years DALE and $44.1 \%$ of total health care spending coming through the public sector; the United Kingdom,

Figure 6

\section{Public Expenditure as \% of Total Health Care Spending}

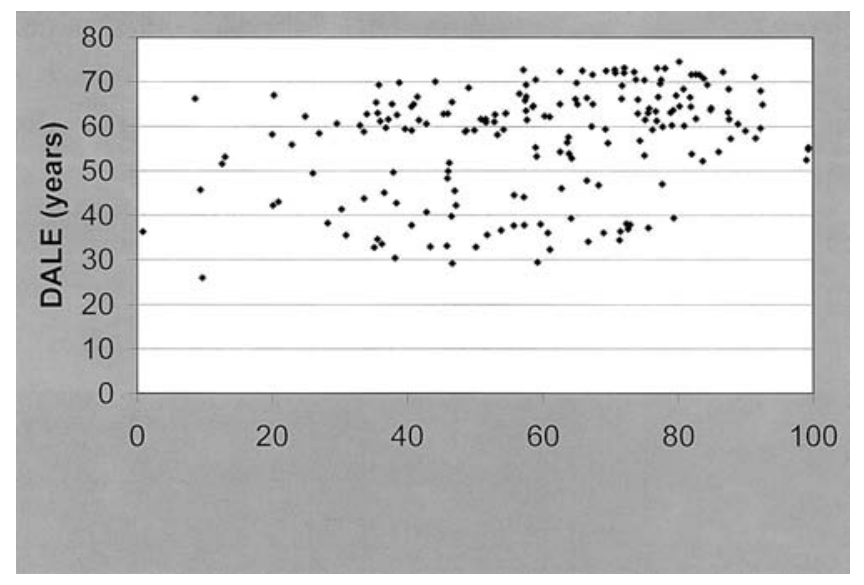

with 71.7 DALE and $82.6 \%$ public spending; and Luxembourg, with 71.1 DALE and 91.4\% public spending (see Table 1 for a complete set of statistics on these systems).

This same wide spread in public versus private spending is characteristic of the larger number of developing nations, generally those with DALEs between 55.0 years and 70.0 years. In this group, the range is from a public-spending high of $99.9 \%$ (Kiribati) to lows of $20.3 \%$ (Uruguay) and $24.9 \%$ (China). The last segment, poor nations, shows the same wide range of public versus private spending for a similarly wide range of outcomes.

Perhaps the most revealing WHO data is presented in Figure 7, which compares the average total per capita health expenditure (in U.S. dollars) to DALEs. A clear pattern emerges from this comparison: Regardless of the "publicness" or "privateness" of a nation's health care system, total spending of about $\$ 1,000$ per capita (1997) is enough to provide a "world-class" health outcome of 70.0 years DALE.

In addition, by focusing on the portion of Figure 7 representing nations with 70.0 or more years of DALE, we see that spending greater than $\$ 1,000$ per capita does not continue to improve a population's health. Our world champion spender-the United States at $\$ 4,187$ per capita per year-actually has slightly worse population health than the United Kingdom $(\$ 1,528$ per capita) does or than the EU average ( $\$ 1,868$ per capita). This begs the questions of why big-spender nations invest extra money on health care and on what it is being spent (see Table 1 for a complete set of statistics).

This overview of data from the WHO (2000) report and our previous discussion of external factors affecting characteristics of national health care systems demonstrate support for a number of important facts:

- Basic health care and public health spending can control infectious disease, problems of childbirth, and injuries that create a disproportionately large burden of disease in developing nations.

- Developed nations' burden of disease is heavily caused by chronic diseases.

- All effective health care systems are, by political choice, mixed public-private systems;

- Spending about $\$ 1,000$ (1997) on health care is needed to produce a "world-class" health outcome (at least 70.0 years DALE). 
Table 1

24 World-Class Health Care Systems and Other EU Member Nations, Ranked by DALE

\begin{tabular}{|c|c|c|c|c|c|}
\hline Rank/Country & DALE & $\begin{array}{l}\text { Disabled } \\
\text { Years }\end{array}$ & $\begin{array}{c}\text { Total Health } \\
\text { Spending as } \\
\% \text { of GDP } \\
\text { (1997) }\end{array}$ & $\begin{array}{l}\text { Total Health } \\
\text { Spending } \\
\text { Per Capita } \\
\text { (US\$ 1997) }\end{array}$ & $\begin{array}{c}\text { Public Spending } \\
\text { as \% of Total } \\
\text { Health Spending } \\
\text { (1997) }\end{array}$ \\
\hline 1. Japan & 74.5 & 6.4 & $7.1 \%$ & $\$ 2,373$ & $80.2 \%$ \\
\hline 2. Australia & 73.2 & 6.4 & 7.8 & 1,730 & 72.0 \\
\hline 3. France & 73.1 & 6.2 & 9.8 & 2,369 & 76.9 \\
\hline 4. Sweden & 73.0 & 6.5 & 9.2 & 2,456 & 78.0 \\
\hline 5. Spain & 72.8 & 6.0 & 8.0 & 1,071 & 70.6 \\
\hline 6. Italy & 72.7 & 6.1 & 9.3 & 1,855 & 57.1 \\
\hline 7. Greece & 72.5 & 5.5 & 8.0 & 905 & 65.8 \\
\hline 8. Switzerland & 72.5 & 6.8 & 10.1 & 3,564 & 69.3 \\
\hline 9. Monaco & 72.4 & 6.8 & 8.0 & 1,264 & 62.5 \\
\hline 10. Andorra & 72.3 & 6.6 & 7.5 & 1,368 & 86.7 \\
\hline 11. San Marino & 72.3 & 6.9 & 7.5 & 2,257 & 73.5 \\
\hline 12. Canada & 72.0 & 7.0 & 8.6 & 1,783 & 72.0 \\
\hline 13. Netherlands & 72.0 & 6.6 & 8.8 & 2,041 & 70.7 \\
\hline 14. U.K. & 71.7 & 5.5 & 5.8 & 1,303 & 96.6 \\
\hline 15. Norway & 71.7 & 6.9 & 6.5 & 2,283 & 82.0 \\
\hline 16. Belgium & 71.6 & 6.3 & 8.0 & 1,918 & 83.2 \\
\hline 17. Austria & 71.6 & 5.8 & 9.0 & 2,277 & 67.3 \\
\hline 18. Luxembourg & 71.1 & 6.9 & 6.6 & 2,580 & 91.4 \\
\hline 19. Iceland & 70.8 & 7.5 & 7.9 & 2,149 & 83.8 \\
\hline 20. Finland & 70.5 & 6.6 & 7.6 & 1,789 & 73.7 \\
\hline 21. Malta & 70.5 & 7.8 & 6.3 & 551 & 58.9 \\
\hline 22. Germany & 70.4 & 6.5 & 10.5 & 2,713 & 77.5 \\
\hline 23. Israel & 70.4 & 6.7 & 8.2 & 1,385 & 75.0 \\
\hline 24. U.S.A. & 70.0 & 6.7 & 13.7 & 4,187 & 44.1 \\
\hline 27. Ireland & 69.6 & 6.7 & 6.2 & 1,326 & 77.3 \\
\hline 28. Denmark & 69.4 & 6.7 & 8.0 & 2,574 & 84.3 \\
\hline 29. Portugal & 69.3 & 7.0 & 8.2 & 845 & 57.5 \\
\hline
\end{tabular}

Source: WHO (2000, Statistical Annex Tables 5 and 8).

- Greater public health care spending, by itself, is not correlated with better health (higher DALE).

- Spending more does not necessarily continue to improve health outcomes.

Figure 7

Per Capita Health Expenditure (US\$), 1997

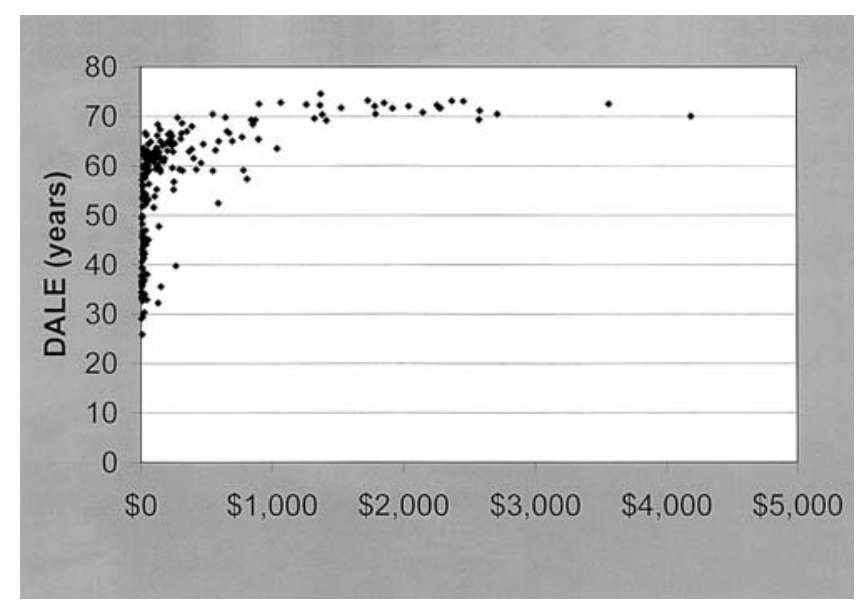

\section{Who Comparison of Health Care SYSTEMS}

The WHO (2000) report contains three different rankings of the world's 191 national health care systems. For each objective of health, responsiveness and financial fairness, WHO has developed measures of population average (goodness) and differences among individuals and groups (fairness). These individual measures are then weighted and ranked into three overall measures.

One ranking is based on measures of what nations have actually been able to achieve with respect to the three objectives (overall attainment). Two other rankings are based on what each system is capable of achieving with available resources (performance)—one measures the single dimension of health performance and the other measures overall performance on all three dimensions of achievement. Table 2 summarizes these three WHO rankings (WHO 2000, Statistical Annex Table 1).

Overall attainment ranks nations on the basis 
Table 2

\section{Health Care Systems Rankings}

\begin{tabular}{|l|l|l|}
\hline \multicolumn{1}{|c|}{$\begin{array}{c}\text { Health } \\
\text { Performance }\end{array}$} & \multicolumn{1}{|c|}{$\begin{array}{c}\text { Overall } \\
\text { Performance }\end{array}$} & \multicolumn{1}{|c|}{$\begin{array}{c}\text { Overall } \\
\text { Attainment }\end{array}$} \\
\hline 1. Oman & 1. France & 1. Japan \\
2. Malta & 2. Italy & 2. Switzerland \\
3. Italy & 3. San Marino & 3. Norway \\
4. France & 4. Andorra & 4. Sweden \\
5. San Marino & 5. Malta & 5. Luxembourg \\
6. Spain & 6. Singapore & 6. France \\
7. Andorra & 7. Spain & 7. Canada \\
8. Jamaica & 8. Oman & 8. Netherlands \\
9. Japan & 9. Austria & 9. United Kingdom \\
10. Saudi Arabia & 10. Japan & 10. Austria \\
24. United Kingdom & 18. United Kingdom & 15. United States \\
72. United States & 37. United States & \\
\hline
\end{tabular}

Source: WHO (2000).

of what they have been able to achieve with respect to health, responsiveness, and financial fairness. Weightings are 50\% health, 25\% responsiveness, and 25\% financial fairness. The health and responsiveness measures are each based on equal weighting of measures of goodness (average) and fairness (distribution).

Overall performance uses the same measures and weighting as overall attainment: But, rather than measuring what each nation has actually accomplished, this ranking measures what national health systems have attained versus their theoretical efficient frontier given available resources.

WHO's last overall system measure is health performance. This ranking focuses solely on health. It measures actual health attainment versus what a system is capable of attaining based on its available resources. Health performance differs from health attainment, which uses DALE to rank nations' health. Health attainment, presented in Figure 4, was discussed previously.

To compare health care systems, WHO develops and uses measures of health, responsiveness, and financial fairness. These measures do not correspond directly to the widely accepted cost, quality, and access goals discussed previously. WHO's approach recognizes the difficulty of adequately defining and directly measuring cost, quality, and access. Health, responsiveness, and financial fairness are definable and measurable; however, using measures that do not directly reflect goals of cost, quality, and access is one reason for criticism of WHO's measures and rankings.
There is, though, a strong, but not always direet, relationship between WHO's measures and universally pursued goals:

- Cost is indirectly captured in the two performance measures of overall performance and health performance, which compare systems' attainments with their theoretical efficient frontiers. Performance is a measure of how well a system does considering the nation's health care resources. These resources are a function of spending. Nations with higher performance rankings can be understood as receiving more benefits for their spending than do lower ranking nations.

- Quality is more directly measured. Health (DALE) and responsiveness directly measure goodness and fairness of fulfilling health care needs and wants.

- Access is measured indirectly, mainly by health (DALE) and fairness (variability) of health, responsiveness and financial fairness: More equal access to health care is reflected in lower variance in these three measures; and, low variance coupled with higher DALE measures better access to higher quality health care.

Thus, data from the report could be combined to measure more directly nations' relative performance in reaching cost, quality, and access goals as measured by WHO standards.

\section{Comparison of Highly Effective Health Care Systems}

Detailed measures of health, responsiveness, and financial fairness are very helpful to better understand differences among national health care systems. Our search for a path toward an ideal health care system uses this data to focus on differences among world-class health care systems, defined for this paper as systems in nations with DALE of 70.0 or more years. This provides us with up to 24 national systems to study.

Fortunately, what we need to understand can be demonstrated by looking more closely at two of these 24 national health care systems: those of the United Kingdom and the United States. These two systems closely represent the extremes. The United States has the largest private-sector system and the United Kingdom one of the largest public-sector systems. 
The following discussion is descriptive in nature; it is not intended as political commentary or value judgment on either the U.S. or U.K. health care systems. As I mentioned previously, the resources a country devotes to health care and the shape of its system are driven by personal importance of health, its social ethic, and its economics and politics. Differences between the U.S. and U.K. systems stem largely from differences in these external factors. My purpose is solely to understand these differences and not to judge the relative merits of each system.

Figure 8 summarizes rankings ${ }^{6}$ and detailed measures of health, responsiveness, and financial fairness in the United States and the United Kingdom and compares them with an average of all EU member nations. The EU average is a helpful point of comparison, since all EU members except Ireland (69.6), Denmark (69.4), and Portugal (69.3) qualify as world-class health care systems.

A very short summary of the U.S. and U.K. systems will suffice for our purposes. Readers not familiar with either or both of these health care systems are referred to the excellent summaries of a wide range of world health care systems prepared by the European Observatory on Health Care Systems. These summaries can be accessed on its Web site at www.observatory.dk.

Health care in the United States is delivered almost exclusively by private sector providers. Many hospitals are owned and operated by forprofit companies; others are not-for-profit or charitable institutions. Physicians and other health care workers are either independent practitioners or work for private-sector health care institutions.

For most Americans, access to health care providers is gained through employment-based private health insurance. Health care for the two largest groups of nonworkers-the nonworking poor and retired citizens-is financed through two large government social insurance programs: Medicaid for the poor (jointly funded by state and federal general revenue) and Medicare for the

\footnotetext{
${ }^{6}$ The rank for each measure in Figure 8 is the numerical rank of the United States and the United Kingdom out of 191 nations in the WHO database. See the Statistical Annex of the report for national rankings.
}

Figure 8

\section{Health Care Systems Performance}

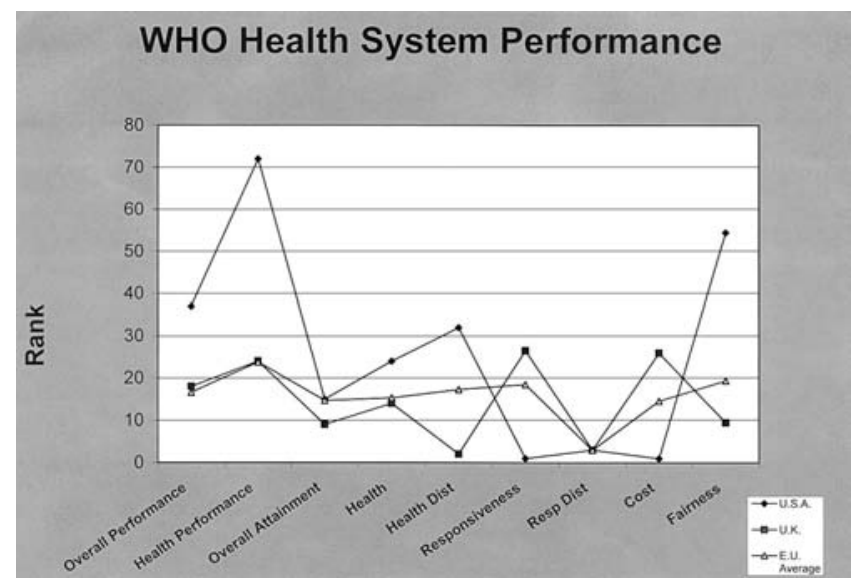

retired population (funded by a federal payroll tax and general revenue).

Through the combination of private health insurance, Medicaid, and Medicare programs, about $84 \%$ of the population is covered. The remaining $16 \%$ of the population, composed mainly of the working poor and their families, must depend on their own (usually inadequate) financial resources or charity care to pay for needed medical care. Needless to say, the level of medical care for uninsured Americans is often substandard and their health is often compromised by lack of adequate care (Institute of Medicine 2002).

The U.S. mix of public and private sector responsibilities has its characteristic strengths and weaknesses. At 70.0 years DALE, the United States is one of the nations with "world-class" health outcomes. The other outstanding characteristic of the U.S. system is its responsiveness: It ranks No. 1 in the WHO survey.

Understanding responsiveness is very important to understanding differences among world-class health care systems. The WHO measurement of responsiveness is based on surveys designed to measure the following (WHO 2000, p. 32):

- Respect for persons: respect for dignity, confidentiality, and autonomy.

- Client orientation: prompt attention, quality of amenities, access to social support networks, and choice of provider.

Survey questions used by WHO researchers to measure responsiveness clearly point to attributes of 
the system that make people feel good about their encounters with providers and, yet, do not seem to affect their health.

Health Attainment (DALE) captures the effectiveness of a national health care system in satisfying its population's health care "needs": Higher DALE is clearly associated with a healthier population. Responsiveness measures capture the intangible health care "wants" that arise from the importance of health eare to individuals' sense of well-being: For a given level of health attainment (DALE), a health care system that is more clientoriented and patient-centered will rank higher in responsiveness. This point is demonstrated by a comparison of the strengths and weaknesses of the U.S. and U.K. health care systems in the following sections.

Distinguishing "wants" from "needs" implies a hierarchy that values national health care systems' addressing their citizens' health care "needs" as more important than health care "wants." This distinction does not imply that fulfilling "wants" is not an important goal for many national health care systems. Countries that successfully fulfill their citizens' health care "needs" uniformly find themselves facing demands for addressing health eare "wants."

While the U.S. system has world-class health results, it actually ranks low in overall attainment (at No. 15). There are three main reasons for this relatively poor performance.

- First, private health care financing, combined with Americans' high expectations for their health care system's responsiveness, is an expensive mix of incentives. The U.S. health care system is by far the most expensive in the world, ranking No. 1 in cost in the WHO database. And, it costs almost twice as much as the U.K. system (measured as a percentage of GDP). While I know of no studies that directly address this observation, anecdotal evidence and data presented in this paper leads me to believe that the U.S. systems' very high responsiveness to Americans' health care "wants" adds significant cost to the system.

- Second, the U.S. health care system is characterized by an incredible variation in quality across its population. At its best, the U.S. health care system is arguably No. 1 in the world-the highest possible quality providers and facilities offering state-of-the-art care with extremely high responsiveness to patients' needs and their nonmedical wants. At its worst, the system is inaccessible to those without health insurance or without easy access to other than low-quality providers and facilities. There is actually a Third-World health care system buried deep within the United States.

- Third, the U.S. system ranks very low in financial fairness. This results directly from the WHO (2000) definition of "financial fairness" emphasizing that ". . . the risks each household faces due to the cost of the health care system are distributed according to ability to pay rather than to the risk of illness" (p. 35). With a system heavily funded by risk-based private health insurance premiums, and with a large number of uninsured Americans who are extremely vulnerable to the high cost of medical care, a low standing for the United States on WHO's measure of financial fairness is no surprise.

In contrast to the United States, the U.K.'s NHI system is a federal tax funded health care system. All U.K. citizens have the right to obtain their health care, at no direct cost to them, through physicians that are salaried employees of the NHI and hospitals owned and operated by the government. The amount of money spent on health is budgeted by Parliament.

NHI and it's constituent pieces determine how their budget is to be spent. In practice, this means that there are waiting lists for certain nonemergency services. While all U.K. citizens have access to NHI physicians and hospitals, $11.5 \%$ of the population bought voluntary health insurance (VHI) in 1998 (Mossialos and Thomson 2001). VHI actually duplicates coverage provided by NHI; however, it provides almost immediate access to physicians and hospitals, thereby bypassing NHI waiting lists (queue skipping).

Not at all surprising, the U.K. health care system has very different strengths and weaknesses from those of the U.S. system (see Figure 8). The U.K. system has far less variation in health outcomes across its population that does the United States, and it ranks much higher than the U.S. system with respect to financial fairness. This outcome is a direct result of the U.K. federal 
tax-based system versus the private risk-based financing in the U.S. system. In addition, the U.K. system is very low cost when compared both to other developed nations' systems and, most conspicuously, to the extremely high-cost U.S. system.

WHO's measures demonstrate that the U.K. health care system has world-class health outcomes, with little variation across its population, and high marks for financial fairness. There is, though, one large negative to this system: It receives relatively low marks for its responsiveness. While the financially unconstrained U.S. system is quite responsive to its citizens "needs" and "wants," the financially constrained U.K. system is much less responsive. With a population DALE of 71.7 years, it is hard to argue that the United Kingdom does not meet it's citizens health "needs" as well as any health system in the world. However, tight control of funding and health resources means that it's citizens more intangible "wants" are constrained, resulting in waiting lists for nonessential medical care and low marks from WHO for responsiveness.

Table 3 provides us with an interesting view from within three world-class health care systems: the United States, the United Kingdom, and Canada. The Chart summarizes opinion surveys on characteristics of the three countries' health care systems obtained from a multinational population survey (Donelan 1999). Significant differences among systems are highlighted in bold.

In all three systems, people share very similar

\section{Table 3}

\section{Public Feedback}

\begin{tabular}{|c|c|c|c|}
\hline & U.K. & U.S. & Canada \\
\hline $\begin{array}{l}\text { Health care system: } \\
\text { Works well } \\
\text { Needs complete rebuilding } \\
\text { Worried about receiving most } \\
\text { advanced medical care } \\
\text { Worried about paying for needed } \\
\text { medical care } \\
\text { Report wait of four }{ }^{+} \text {months for } \\
\text { elective surgery } \\
\text { Report having problems paying } \\
\text { medical bills } \\
\text { Report last M.D. visit as } 10 \\
\text { minutes or less } \\
\text { Believe overall medical care was } \\
\text { excellent/very good }\end{array}$ & $\begin{array}{l}25 \% \\
14 \\
46 \\
37 \\
33 \\
3 \\
65 \\
50\end{array}$ & $\begin{array}{l}17 \% \\
33 \\
47 \\
47 \\
1 \\
18 \\
30 \\
49\end{array}$ & $\begin{array}{l}20 \% \\
23 \\
63 \\
45 \\
12 \\
5 \\
33 \\
54\end{array}$ \\
\hline
\end{tabular}

Source: Donelan et al. (1999). opinions that their own overall medical care is very good to excellent and express confidence in receiving the most advanced medical care. However, while U.K. citizens express a relatively strong support for their system, Canadians and Americans are far more likely to be critical of their systems.

When asked about direct experiences with health care providers and financing, there are distinct differences in responses across surveyed countries that are consistent with what we have learned from the WHO rankings discussed above. U.K. survey respondents report virtually no worry about paying medical bills. They do, though, report long waits for surgery and short physician office visits. These results refer to responsiveness issues and not to truly needed medical care. In contrast, U.S. respondents report no wait for care and longer office visits while worrying much more about paying for their care.

By delving more deeply into the U.S. and U.K. health care systems, we gain perspective on the characteristics of world-class systems. This analysis demonstrates support for a number of important facts and observations:

- Developed nations with world-class health outcomes (DALE $\geq 70.0$ years), which include both U.S. and U.K. health eare systems, all spend "enough" on health care to satisfy their populations' health care "needs."

- Additional spending on health care tends to improve responsiveness (i.e., "wants") more than health outcomes (i.e., "needs").

- Health is so essential and sensitive to individuals that even the best health care systems have difficulty managing their public's concerns and expectations.

- Public programs like those in the United Kingdom are increasingly having financial constraints that make it difficult to provide for their citizens' health care "wants."

A growing demand for fulfilling health care "wants," which can be quite expensive, points to a developing role for private health insurance as a "safety valve," providing for those health care "wants" that exceed real health care "needs." This last point will be more fully explored in the remainder of this paper. 


\section{Public or Private Health Financing: Which Approach Works Best?}

Designing a world-class health care system inevitably requires choosing between or mixing public and private approaches, most particularly in financing. Which choice or mix makes most sense depends in large part on the characteristics of public and private health care financing. Understanding the significant differences in the performance of public and private markets requires a digression into the economic of insurance markets.

Private insurance markets have been widely studied by some of this era's prominent economists, including Nobel Laureates Kenneth Arrow, Milton Friedman, Joseph Stiglitz, and Daniel Kahnemann. Economists' interest in insurance markets stem from three main concerns:

- First, private insurance markets behave in a very strange economic manner. They are characterized by information asymmetry, that is, a meaningful difference in information between buyers and sellers. Stiǵlitz won the 2001 Nobel Prize in Economics for his work in describing markets with asymmetric information (see Rothschild and Stiglitz 1976). In the case of insurance, asymmetric information has to do with risk characteristics. Obviously, buyers (consumers) know much more about their risks than do sellers (insurance companies). How information asymmetries affect markets is of great interest not only to economists, but also to actuaries who must understand and manage the consequences of market anomalies.

- Second, economists are interested in understanding if a good or service is best produced in the public sector or private sector. Insurance (protection) is one service that is commonly found in both sectors. So, economists turn their attention to understanding the relative merits of public versus private insurance. Financing health care is clearly one of the main areas of their exploration. Arrow (1963), another Nobel Prize winner, is known for his work in this area.

- Third, economists have been interested in how individuals and businesses make risky decisions. Friedman and Kahneman, more recently, explored this subject using insurance purchase as one of their considerations (see Friedman and Savage 1948 and Kahneman and Tversky 1979).
As Arrow and Stiglitz both inform us, privatevoluntary insurance markets are characterized by "market failure" : incomplete insurance due to the inability of these markets to shift all the risk of any economically relevant event (Arrow 1971). This idea should sit well with actuaries, since we are all aware of it from our daily experiences of uninsurable risks and the need for cost sharing in insurance contracts.

In their seminal work on markets with asymmetric information, economists Michael Rothschild and Joseph Stiglitz (1976) describe market failure in even more disturbing terms:

"Economists generally prescribe competition as a solution for markets that do not work well .... Insurance markets differ from most other markets because in insurance markets competition can destroy the market rather than make it work better" (p. 73).

Understanding the market dynamic that lead Rothschild and Stiglitz to make this very strong and truthful statement is beyond the scope of this paper.

Economists describe two underlying reasons for market failure: (1) adverse selection, arising from asymmetric information, and (2) moral hazard. Actuaries are quite familiar with both of these problems and work daily on managing their consequences.

Adverse selection occurs when bad risks buy insurance and good risks choose not to purchase insurance. Adverse selection can occur if the insurance company cannot distinguish good risks from bad risks. The consequences depend on degree. Some well-known consequences of adverse selection range from higher premiums for insured risks when a product or market is subject to a mild degree of adverse selection to complete failure of a product, insurer, or market when a high degree of adverse selection develops. Actuaries have developed sound risk management tools to

\footnotetext{
${ }^{7}$ Market failure is used by economists to describe a characteristic that private-voluntary insurance markets often do not shift all risks that consumers want to insure. For example, while not usually thought of as a problem, deductibles, copayments, limitations, exclusions, and benefit maximums all are examples of economic market failures. Examples of economic market failure that fit better with non-economic understanding are the non-existence of a market for insurance, or the collapse of an existing market.
} 
cope with adverse selection. These include risk selection (underwriting), risk rating, and various risk renewal techniques (policy terms and rates).

Moral hazard is the other underlying market malady. Moral hazard occurs because ". . . (T)he insurance policy itself might change the incentives and therefore the probabilities upon which the insurance company has relied" (Arrow 1971, p. 142). This too is a very familiar problem to actuaries. We have developed risk management tools such as underwriting benefit limits in relation to risk, deductibles and copayments, and managed care to control the escalating frequency and severity of health insurance claims.

Without effective risk management tools, the Rothschild and Stiglitz (1976) warning of competition destroying insurance markets would be far more pervasive than we actually experience. However, even with effective risk management tools, we will see that adverse selection and moral hazard characterize and constrain performance of private insurance markets when compared to public insurance systems.

\subsection{Private-Voluntary Insurance Markets}

Private-voluntary insurance markets are characterized by choice. Consumers have complete freedom to buy or not to buy insurance. Multiple competing insurers, too, have their own choices of whether or not to offer insurance and much freedom over their terms of coverage. Privatevoluntary markets can be illustrated by describing a well-behaved market situation with no negative consequences of adverse selection or moral hazard. In this well-behaved state, a subset of the universe of potential consumers chooses to buy insurance from all insurers competing for its business, and, a subset of those consumers choosing to buy insurance chooses coverage from insurer A. Under these ideal conditions, average loss frequency and severity is the same for each of our three sets: Insurer A has the same average loss experience as all insured customers (all insurers) who, in turn, have the same average losses as the entire universe of potential insureds.

However, actuaries will quickly recognize the ideal nature of this depiction. It is quite likely that the consequences of adverse selection and moral hazard will cause the losses for all insureds to be higher than those of the universe of potential customers. And, even more likely, a single insurer competing in the market may have its own loss differ, perhaps significantly, from overall market losses and from those of other insurers. Thus, a familiar dynamic of private-voluntary markets can be summarized as follows:

- As a consequence of choice, adverse selection and moral hazard naturally arise in privatevoluntary markets to lesser or greater degree.

- Choice causes uncertainty about the level of risk borne by all insurers.

- Choice causes uncertainty about the level of risk borne by each insurer that competes in the market.

- Competition among insurers, adverse selection, moral hazard, and buyers' pursuit of their own best interests in making their insurance purchasing decisions shape market behavior.

To compensate for potential negative consequences of adverse selection and moral hazard, insurance companies must develop and use effective risk management tools. These tools include risk selection, risk rating, and renewal risk management. However, risk management tools often cause problems for bad risks:

- Bad risks may not be able to obtain insurance, making universal coverage impossible to attain (risk selection).

- Bad risks may pay more for their insurance than good risks do, making the sick pay more for their insurance than the well (risk rating).

- Bad risks may be treated differently at renewal or have restrictions on moving from one insurer to another, leading to charges of heavy-handed rating practices by insurers and problems such as "job lock," where employees cannot move from one job to another without the threat of losing their health insurance (renewal risk management).

Given strong individual and societal sensitivities to health and health care, the negative consequences of these necessary private-market risk management tools often are viewed as unacceptable behavior on the part of insurers. The public, press, and politicians focus their critical comments on the natural negative consequences of private-voluntary market behavior and not on the 
underlying market structure that causes this symptomatic behavior.

Growing concerns can lead to a loss of public confidence in health insurers, spirited media and political charges against insurance company behavior, and, finally, to regulation of health insurers and health insurance products. Practices that are tolerated in other less sensitive insurance markets (e.g., risk selection and risk rating for life insurance) are not long tolerated in health insurance markets due to the particular sensitivity of "health" as an insured risk.

\subsection{Public-Mandatory Insurance Markets}

In stark contrast to the nature of private-voluntary insurance markets, public-mandatory markets have quite different characteristics. Publicmandatory markets are characterized by a lack of choice. This type of market arises when a government uses its power to mandate that the entire universe of potential consumers be covered for insurance and arranges financing and insurance in publicly acceptable ways to accomplish this objective. The U.K.'s NHI and the U.S.'s Medicare program are two examples of successful publicmandatory markets.

The key difference between private-voluntary markets and public-mandatory markets is that by eliminating choice, public-mandatory social insurance programs eliminate adverse selection. When the entire universe of risks is covered in a single risk pool, uncertainty about the level of risk is caused by choice is totally eliminated. Moral hazard, though, is not eliminated in public programs. It continues to exist as a cause of market failure.

The consequence of public-mandatory markets is that programs using this structure do not need to develop the wide range of risk management tools that characterize private-voluntary markets.

\footnotetext{
${ }^{8}$ Examples of how critically these risk management practices are viewed by the public are common in the U.S. press, particularly when health care reform becomes a national political issue. Three particularly critical articles from the past decade are: "Unsurance," by Constance Mathiessen (Hippocrates, November/December 1989, pp. 3646); "Insurance: The Death Spiral," by Jane Bryant Quinn, (Newsweek, Feb. 22, 1993, p. 47); and "Insurance Tactic: If You Get Sick, The Premium Rises," by Chad Terhune (Wall Street Journal, April 9, 2002, p. 1).
}

Risk selection is not necessary due to the mandatory nature of these programs. Risk rating is unnecessary since government can use its taxing powers and other tools to raise funds and does not need to be concerned with the adverse selection consequences of actuarial rating systems. And, by setting up a single risk pool that eliminates movement among competing risk pools, public programs do not need renewal risk management tools to compensate for adverse selection.

Insurance market structure predictably drives consumer and insurance company behavior, which in turn results in the use by insurers of characteristic risk management tools. Another way to look at this fundamental insurance market dynamic is that actors in insurance markets are bound by the role dictated to them by market structure. To change the behavior of consumers or insurance companies fundamentally, government needs to create proper market structures. This is precisely how government exercises its stewardship of health insurance markets.

Table 4 summarizes the strengths and weaknesses of private-voluntary markets versus public-mandatory markets. In addition to the points discussed above, the table also captures information on the types of benefits (private markets are more responsive), administrative costs (public markets are less costly_there are no marketing, underwriting, or renewal costs), and quality of administration (public programs are bureaucratic).

\section{Table 4}

\section{Comparative Performance}

\begin{tabular}{|c|c|}
\hline Private-Voluntary System & Public-Mandatory System \\
\hline $\begin{array}{l}\text { Strengths } \\
\text { - Choice (responsiveness) } \\
\text { —Expansive "wants" } \\
\text { benefits } \\
\text { - Available to most } \\
\text { customers willing to pay an } \\
\text { equitable cost for coverage } \\
\text { - Private control of } \\
\text { decisions over provision } \\
\text { of health care } \\
\text { Weaknesses } \\
\text { - Universal coverage } \\
\text { impossible } \\
\text { - Fragmentation of risk pool } \\
\text { —"Cherry-picking" } \\
\text { - High sales and } \\
\text { administrative costs } \\
\text { - Risk-rated premiums } \\
\text { - Challenge to limit costs }\end{array}$ & $\begin{array}{l}\text { Strengths } \\
\text { - Universal coverage } \\
\text { - Direct cost control } \\
\text { through government } \\
\text { budgets } \\
\text { - No market fragmentation } \\
\text { - Tax-salary based financing } \\
\text { (financial fairness) } \\
\text { - Low overhead costs } \\
\text { Weaknesses } \\
\text { - Bureaucracy } \\
\text { (unresponsiveness) } \\
\text { - Not likely to provide all } \\
\text { health care "wants" } \\
\text { demanded by public } \\
\text { - Strong public involvement } \\
\text { in provision of medical } \\
\text { care services (may be } \\
\text { considered a strength) }\end{array}$ \\
\hline
\end{tabular}


The private-voluntary and public-mandatory market structures as described in this section take their simplest form. In reality, government has the ability to regulate private-voluntary markets so that they function more like public-mandatory markets and vice versa. Examples of these regulated markets exist throughout the world. The value to us of discussing simple models is to help clearly understand the design and functioning of more complicated market structures.

From this discussion, we glean a number of important facts.

- Private-voluntary markets are not structured to be capable of providing universal coverage or tax-based financing.

- In response to adverse selection and moral hazard, insurers and customers in private insurance markets will naturally exhibit a range of unattractive market behavior.

- Public markets, or their structural equivalent, are needed to provide universal coverage and to allow for use of tax-based or other nonriskbased funding.

- Private markets, subject to adequate stewardship, are the most appropriate means to fund voluntary health care benefits that satisfy "wants" rather than "needs."

\section{An Ideal Health Care System}

To this point we have discussed nonmedical sensitivities toward health care systems; compared the effectiveness of the world's 191 national health care systems; delved in more detail into the characteristics of two very different large, world-class systems (U.S. and U.K.); and explored the economics of how public and private insurance markets differ in their risk bearing capacities and characteristic risk management tools.

These considerations were explored with the intention of providing information needed to address the primary goals of this paper: creating a high-level template for turning the goals discussed in Section 3 into operating structures for the stewardship and financing of an ideal worldclass health care system.

Our structure is necessarily a high-level one. We must leave sufficient room for nations to incorporate their own human sensitivities, politics, and ethics. These nonmedical human and societal differences are incorporated, directly by gov- ernment intervention or indirectly through functioning private markets, into the design of any and all nations' health care systems. There, then, cannot be a "one-size-fits-all" design for a worldclass system. Despite these important restrictions, there is much that we can say about designing world-class health care systems.

\subsection{Principle 1}

Health care systems need enlightened stewardship. The most basic lesson from our exploration is that government stewardship of health care systems is necessary. We have discussed how important nonmedical considerations and market structure are to a health care system. It is virtually impossible to conceive how these matters can be incorporated into a health care system without government stewardship through its legislative and executive functions.

The need for stewardship of public health care plans is clear. Stewardship is not, though, limited to public programs. We have seen in our discussion of private-voluntary markets that, without enlightened regulation of health insurance (i.e., government stewardship), universal access to medical care is virtually unattainable. This is true because risk management tools needed to provide market stability restrict access to insurance for bad risks and raise their risk-based premiums. Whether totally public, totally private or mixed public-private health care systems, nations need enlightened stewardship.

\subsection{Principle 2}

The base of an ideal system is a universal health care program providing for citizens' medical care "needs." Universal access is consistent with a social ethic of social solidarity in providing at least basic medical care services to all citizens. ${ }^{9}$ Given the market failure problems that characterize private-voluntary markets, there are only two potential market structures that can provide universal coverage:

\footnotetext{
${ }^{9}$ Debate over universal access to health insurance has occurred periodically in U.S. health care reform debates. Americans espouse support for universal access, but is unwilling to support changes needed to reach this goal. Congress has consistently failed in its attempts to enact reforms.
} 
- A public-mandatory market structure with taxbased and/or employment based funding, or

- A government regulated private-mandatory market structure in which the purchase of private insurance coverage is made legally mandatory for all citizens.

In the case of a government-created private-mandatory market, law and regulation must be geared to minimize and properly compensate for remaining aspects of risk selection, risk rating, and renewal risk management that run counter to smooth functioning of a universal health insurance system. This can be done, but not without careful thought and effective government stewardship of private-sector health insurers and their use of risk management tools.

In the discussion of goals for health care systems, I noted how there is a growing consensus in developed nations that funding all health care that citizens both "need" and "want" is increasingly beyond governments' resources. This fiscal constraint means that health care systems will benefit from the difficult task of clearly differentiating medical care that is "needed" for citizens to achieve world-class outcomes from medical and nonmedical "wants" that, while valued by patients, do not add to population health.

\subsection{Principle 3}

The needs-based universal core program is supplemented by private health insurance covering health care "wants." Having defined differences between health care "needs" and "wants," an ideal public universal health care system should cover population "needs" and leave funding for and coverage of population "wants" to an adequately regulated private-voluntary health insurance market.

A social ethic of liberty and autonomy drives the need for an ideal system to make available the opportunity for citizens to voluntarily purchase a higher level of benefits than can be afforded by a nation's universal health care system. While this two-tier health care system makes sense at a conceptual level, we must clearly note that it is very difficult to define "needs" versus "wants."

\subsection{Principle 4}

There needs to be a seamless, nonduplicative interface between universal needs-based and voluntary wants-based parts of the health care system. Those charged with stewardship of the system need to design this interface carefully, which also is not an easy task.

European countries already have a variety of examples of universal coverage and supplemental private health insurance (Mossialos and Thomson 2001). To my knowledge, though, none of these countries has found a good solution to how a two-tier health care system with both universal and voluntary parts can work to fulfill and fund their citizens' complete health care "needs" and "wants."

\subsection{Principle 5}

The health care system must have adequate medical care resources, and it must be flexible and able to adapt to new health care technologies and new medical care needs. Even if we were to be able to describe our ideal health care system in detail, we would have to admit that any current solution will eventually need to change. As medical research continues to drive new technology, and as countries grow richer and their citizens value more and more medical care, so too will the boundary between "needs" and "wants" change.

An artificial heart is an example of this dynamic. As artificial heart technology improves, will this extremely expensive medical intervention be made available and, as it becomes more effective and common, will it ultimately change from a "want" to a "need?" This single example should amply demonstrate to the reader the ethical, political, technical, medical, financial, and emotional issues that will continue to challenge health care systems. An ideal system must have strong stewardship and be flexible enough to allow it to adapt to continuous change in medical care technology and its implications for citizens and the system itself.

\subsection{Principle 6}

Our ideal system must allow each nation to meet its health care goals for cost, quality, and access in ways consistent with its financial capacity and its personal, social, economic, and political health care drivers. Our ideal health care system supports national goals for cost, quality, and access, but does so leaving a great deal of flexibility 
for nations to adapt systems to their environment.

- Cost is addressed by focusing a universal program on population health care "needs" while allowing citizens' "wants" to be satisfied by purchasing private supplemental health insurance. While this split funding does not solve problems caused by escalating health care costs, it does allow government latitude to control publicly financed care costs by shifting some costs to the private sector.

- Quality is more directly addressed. A universal program covering citizens' health care "needs" will maximize population health (DALE) and minimize variations. Quality "demands" arising from citizens' health care "wants" are mostly, but not completely, satisfied through private supplemental health insurance. Satisfaction of "wants" will depend on the breadth of private coverage, and on the popularity and affordability of its premiums.

- Access to needed medical care is assured by a universal health care system. Access to more responsive care is available through the purchase of private supplemental insurance.

\subsection{Principle 7}

Developing countries need to consider today the evolution of their health care systems. Designing an ideal world-class health care system is not only difficult, but also expensive. Our discussion of an ideal system implicitly speaks only to those countries that can afford roughly $\$ 1,000$ (1997) per capita in health care expenditures. Many countries simply cannot afford this financial burden right now, and some likely will not be able to afford anywhere near this amount for the foreseeable future. These countries clearly are not at a point to consider many of the issues concerning design and implementation of an ideal health care system.

Our analysis does contain two important lessons for developing countries, though. First, it is necessary to think clearly now about the future and how a developing country's health care system will be organized as it becomes more fully funded. The reason for this is that not doing so may create markets, usually private-voluntary health insurance, that may currently work well but also may create entrenched political and societal barriers to later change.

Second, looking back to Figure 5, note the vast difference in the causes of morbidity between developed nations and developing nations. Developing nations' burden of disease is heavily weighted toward infectious disease, diseases of childbirth, and accidents. There has been a great deal of thinking done about how to address this morbidity profile (Sachs 2001). Researchers note that much of this disease burden is amenable to basic public health intervention.

\section{Actuaries Can Help}

Implementing an ideal health care system requires a great deal of additional thought and planning. How can actuaries help? Actuaries are trained in understanding and modeling public and private system's responses to varying incentives, policy and administrative options, and in communicating costs and consequences to relevant audiences. Actuaries are trained in gathering data and using it to refine health care systems' policies and operations (the actuary control cycle). Actuaries are trained in the consequences of private-sector insurance regulations and in how to price benefits and policy options for both public- and private-sector health plans.

Figure 9 is an adaptation of the actuarial control cycle to an overview of stewardship of health care systems. Actuaries have particular expertise in the technical effectiveness and efficiency of how systems operate, measuring outcomes, and providing feedback to those responsible for stew-

Figure 9

Toward a Better Health Care System
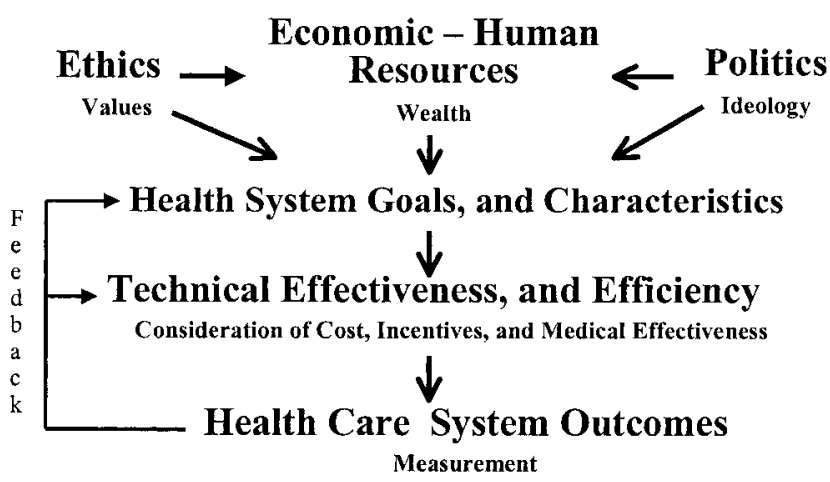
ardship of the system. However, actuaries are not trained in ethics, health policy, or politics. We serve the public best in those areas by expressing our informed opinions solely as concerned citizens.

In performing these functions, actuaries often encounter other trained professionals, notably health economists, health statisticians, and health policy analysts. Their skill sets and ours often overlap. This makes it difficult to argue that actuaries are in a unique position to make contributions to nations' health care systems. However, while we must recognize this overlap in skills, our training in the practical consequences of policy options and in gathering and analyzing data do put us in a position to be of great value to those responsible for the stewardship of health care systems and to the private health insurance companies that choose to participate in the market.

National actuarial organizations can help to promote the role of actuaries in national health care systems by becoming known to health policymakers and to those responsible for stewardship. National organizations can provide information on the actuarial aspects of health policy issues and also promote the hiring of actuaries in national health systems and in insurance regulatory bodies.

The International Actuarial Association (IAA) also has a role to play. International organizations such as WHO, OEDC, and the World Bank are engaged in thinking about health care systems. The IAA can play a role by promoting actuarial input to these organizations' health policy staff, conferences, and journals. By creating more opportunities for skilled health actuaries to provide input, actuaries can make a difference.

\section{References}

Almeida, C., ET Al. 2001. "Methodological Concerns and Recommendations on Policy Consequences of the World Health Report 2000," The Lancet 357, (May 26): 1692-7.

Arrow, K. J. 1963. "Uncertainty and the Welfare Economics of Medical Care," American Economic Review 53: 941-73.

- 1971. "Insurance, Risk and Resource Allocation," in Essays in the Theory of Risk-Bearing, Chapter 5, pp. 134143, Chicago, Markham.

Beveridge, W. 1942. Social Insurance and Allied Services. London: HMSO. Reprinted in Bulletin of the World Health Organization, 2000, 78 (6).

Bolnick, H. J. 1995. "The U.S. Health Care Reform Odyssey," Contingencies (July/August): 28-33.
British Medical Journal. 2001. Report on presentations at the Fourth European Health Forum in Bad Gastein, Austria 323 (Oct. 6): 772.

Callahan, D. 1998. False Hopes: Why America's Quest for Perfect Health Is a Recipe for Failure. New York: Simon \& Schuster.

Donelan, K., ET AL. 1999. "The Cost of Health System Change: Public Discontent in Five Nations," Health Affairs (May/ June): 206-216.

Friedman, M., and L. J. Savage. 1948. "The Utility Analysis of Choices Involving Risk," The Journal of Political Economy 56(4): 279-304.

Institute of Directors. 2000. Healthcare in the UK: The Need for Reform. London: Institute of Directors.

Institute of Medicine. 2002. Care Without Coverage: Too Little, Too Late. Washington, DC: National Academy Press.

Kahneman, D., And A. Tversky. 1979. "Prospect Theory: An Analysis of Decision under Uncertainty," Econometrica 47(2): 263-292.

KInG, L. W. TRANs. 1910. Hammurabi's Code of Law. Online at http://wrww.wsu.edw/dee/MESO/CODE.HTM.

Mordacci, R., And R. Sobel. 1998. "Health: A Comprehensive Concept," The Hastings Center Report (January/February): 34 .

Mossialos, E., and S. M. S. Thomson. 2001. Voluntary Health Insurance in the European Union, London School of Economics Health and Social Care Discussion Paper No. 19, May.

Murray, C. J. L., And A. D. Lopez. EDS. 1996. The Global Burden of Disease and Injury. Cambridge, MA: Harvard School of Public Health on behalf of the World Health Organization and the World Bank. Summary online at http://wwrw.hsph. harvard.edu/organizations/bdu/summary.html.

Rothschild, M., And J. Stiglitz. 1976. "Equilibrium in Competitive Insurance Markets: An Essay on the Economics of Imperfect Information," Quarterly Journal of Economics 90(November): .

Rothschild, M., and J. STiglitz. 1997. "Competition and Insurance Twenty Years Later", The Geneva Papers on Risk and Insurance Theory, 22: 73-79.

SAchs, J. D. 2001. "Macro Economic and Health: Investing in Health for Economic Development." Report of the Commission on Macroeconomics and Health.

Starr, P. 1982. The Social Transformation of American Medicine. New York: Basic Books.

Williams, A. 2001. "Science or Marketing at WHO?: A Commentary of 'World Health 2000,'" Health Economics 10: 93100.

World Health Organization (WHO). 2000. The World Health Report 2000. Geneva: WHO Office of Publications.

Discussions on this paper can be submitted until October 1, 2003. The author reserves the right to reply to any discussion. Please see the Submission Guidelines for Authors on the inside back cover for instructions on the submission of discussions. 